\title{
Desire and Coping Self-Efficacy as Craving Measures in Addiction: The Self-Efficacy and Desire Scale (SAD)
}

\author{
Iacopo Minervini ${ }^{*}, 1$, Silvia Palandri ${ }^{1}$, Stefano Bianchi ${ }^{1}$, Luca Bastiani ${ }^{2}$ and Donatella Paffi ${ }^{1}$ \\ ${ }^{I}$ Drug Addiction Service (SerT) AUSL 5 Pisa, Italy \\ ${ }^{2}$ National Research Institute (CNR), Pisa, Italy
}

\begin{abstract}
Craving is closely interconnected with substance addiction. Its precise role of mediator or indicator is frequently discussed, although it has also been identified as a relevant factor in continued substance use and relapse after stopping. The assessment of craving is particularly complex because different theories adopt different methodologies and measures. Desire to use and the loss of control of use are frequently adopted as constructs within instruments.
\end{abstract}

The control of substance use can conceptually be developed in Coping self-efficacy, defined as ability to resist substance use in high-risk situations. There is strong evidence in literature about craving as an important factor that supports remission and reduces relapse risk. More specifically, a high sense of coping self-efficacy to resist substance use at treatment intake, during treatment, and/or after treatment discharge, is a stable predictor of better results in alcohol and substance use.

The Self-efficacy scale and desire (SAD) is an Italian language self-report instrument with 27 items assessing desire for a specific substance of abuse (heroin, cocaine) and the perceived ability to resist use (Coping self-efficacy).

It is possible to calculate a score for Desire scale and for Coping self-efficacy scale and a score for three sub-scales: Positive emotions and social situations, Negative emotions and potentially critical situations, Habit and abstinence, each with nine items.

Results of validation process highlight an excellent internal consistency measured by Cronbach coefficient for both scales. Split-half reliability and convergent validity with Visual Analogue Scale for craving measurement were also explored.

Structural Equation Modelling with inductive/confirmative validation approach showed an excellent data adjustment.

Keywords: Craving, self-efficacy, coping, relapse situation, drug.

\section{INTRODUCTION}

\section{Craving: Dimensional or Multidimensional Measure- ment?}

Although there is a clear relationship between craving and substance addiction, the nature of craving has been intensely debated $[1,2]$. Craving is an indicator of addiction and relapse and is often used as an outcome measure in drug treatment research. Nevertheless, its exact role of mediator or indicator remains controversial $[3,4]$. Many studies fail to outline a strong correlation between craving and substance use and there are further studies that fail to indicate craving as a relapse precursor. Contradiction between the conventional concepts of craving and literature can be attributed, among various factors, to inadequate measures of craving $[1,2]$. Indeed, craving assessment is particularly difficult because there are different concepts regarding measurement methodological aspects [5-9]. One-dimensional or multidimensional instruments can measure craving [7,10-12]. The drawback of one-dimensional measure concerns psycho-

*Address correspondence to this author at the Servizio Tossicodipendenze (SerT), AUSL 5 Pisa, via delle Torri 160, 56100 Pisa, Italy; Tel: +3950954964; Fax: +3950954950; E-mail: iacopominervini@libero.it metric issues and a more general criticism regarding a single item that struggles to grasp different dimensions that theoretical models of craving surmise. Although one-dimensional items possess desirable characteristics such as clarity, brevity, minimum patient discomfort, are often inadequate. Visual analogue craving scales continue to be the most popular method for measuring craving [13-15]. They are limited to a definition or aspect of craving and methodologically, contain more error variance than broader measures [1]. Internal consistency and reliability can be calculated only for multi-items measures: these have better psychometric characteristics and better differentiate craving levels in critical situations and environments [16]. Multi-item tools allow to identify different ways in which individuals, in various stages of addiction, experience craving.

Many studies compare single item with multi-item instruments $[17,18]$. These studies suggest that multi-item and multi-dimensional measures better predict retention treatment in cocaine and heroin abusers [17], recent substance use [18] and are able to monitor craving during treatment because they are more sensitive in eliciting change in comparison to single-item measures [19]. Length is one limitation of multi-item instruments. Generally, they are powerful psychometric tools and provide multifactorial assessment yet their length limits use in many areas. 
Desire to use substance and lack of control of use appear as central dimensions in several instruments.

Control over substance use can be conceptually developed in Self-efficacy construct. It is defined as the individual's belief to be able to dominate specific activities, situations or psychological and social functioning [20-24]. In literature on addiction it is defined as coping Self-efficacy: the perceived ability to resist in a high-risk crisis and/or relapse situations [25]. Several instruments focus on beliefs in the ability to refrain using tobacco and other substances, measuring individual confidence to avoid specific substance use in defined situations [25-29].

There is strong evidence that individual Self-efficacy to resist or confidence in avoiding substance use in high-risk situations, is a supporting remission key factor and reduces relapse risk [30-36]. Specifically, high Self-efficacy in substance use resistance at treatment intake [37,38], during treatment [39], and/or after treatment ending [40-42], is a stable predictor of better results in alcohol and substances use.

This paper proposes a craving scale assessment validation, named "Self-efficacy and desire scale" (SAD) - Italian version, which measures Desire and Coping self-efficacy through potentially risky situations of crisis and relapse presentation.

The aim of this work is the validation of SAD through instrument administration to a sample of subjects in order to make both items and sub-scales statistically valid for a clinical use. Finally, we intend to standardize administration procedures, instructions and assessment operations and score allocation.

\section{MATERIALS AND METHODOLOGY}

\section{Self-Efficacy and Desire Scale on Craving}

Self-efficacy and desire scale has versions for heroin and cocaine. Versions differ only for related substance terms; they are identical for all the rest. The scale has 27 items describing different situations, within each of which the subject must indicate, in a first column, substance desire level and, in a second column, substance use perceived resist ability. Items are formulated trying to promote good understanding, avoiding ambiguity, technical language or extremely complex items. A dash line separates two columns and indicates the way to fold the sheet along this line allowing the patient to focus on one construct at a time (perceived desire level first and then self-efficacy) preventing him to look at previously allocated values.

Instructions require a careful evaluation of desire and resist ability of the previous week (see Table $\mathbf{1}$ ).

A 10-point scale with format response at intervals of 1 unit: from 0 to 10 is at the top of the scale. Meanings of score levels vary in relation to:

- Substance desire: from 0 "minimal desire" to 10 "maximum desire".

- Resist substance use perceived ability: from 0 “ minimal ability to resist" to 10 "maximum ability to resist".
Table 1. Scale Initial Instructions (Heroin Version)

The following items describing different situations.
First column indicates desire level to use heroin while second column
indicates how able you feel to resist heroin use. Pay attention to judge
desire and resist use ability during last week.
Minimum
desire
\begin{tabular}{|c|c|c|c|c|c|c|c|c|c|c|}
\hline $\mathbf{0}$ & $\mathbf{1}$ & $\mathbf{2}$ & $\mathbf{3}$ & $\mathbf{4}$ & $\mathbf{5}$ & $\mathbf{6}$ & $\mathbf{7}$ & $\mathbf{8}$ & $\mathbf{9}$ & $\mathbf{1 0}$ \\
Minimum \\
resist use \\
ability
\end{tabular}

Administration has an average duration time of 9 minutes (we observed a range of 6-15 minutes), while score calculation can be easily carried out with an excel spreadsheet in approximately three minutes.

\section{The Construct Multidimensionality}

It is possible to calculate a total score and a score for three sub-scales (Positive emotions and social situations; Negative emotions and potentially critical situations, Habits and abstinence), each consisting of nine items (see Table 2 for item examples):

- $\quad$ Positive emotions and social situations with reference to recreational situations, social, emotionally positive and low stress.

- $\quad$ Negative emotions and potentially critical situations with reference to emotionally negative situations, stress and anxiety for the subject.

- Habits and abstinence with reference to habits related to the intake of substances and internal drive components pushing the person to substance use.

Subjects who show similar convictions for Self-efficacy develop a more general competence feeling and efficiency. Yet the more one extends activity/situation scopes (which refers to personal effectiveness judgement), the less one can predict specific behaviour in different contexts given that it is unlikely that a person will invariably produce the same performance level or perceive the situations in the same way. Unlike other instruments with a unitary construct leading to a single scale score, we can develop three additional subscales. Particular attention was paid to build items that would highlight different difficulty ranges and, along with construct multidimensionality, guarantee an adequate response differentiation and therefore a reliable tool of assessment of desire level and coping self-efficacy.

\section{METHOD}

The scale was analysed with descriptive methods highlighting medium and standard deviations and, subsequently, through comparisons between medium. Successively, the analysis of internal consistency and validity convergent with a Visual Analogue Scale for the measurement of craving (VAS) was presented.

Finally, we used a structural equations method with an inductive/confirmatory validation of the following assumption: subscales converge towards two latent factors called Desire and Coping self-efficacy, negatively correlated with 
Table 2. Examples of Item and Subscales (Heroin Version)

\begin{tabular}{|l|l|}
\hline \multicolumn{1}{|c|}{ Subscale } & \multicolumn{1}{|c|}{ Examples of item } \\
\hline \hline Positive emotions and social situations & 1) When I drink alcohol more than ordinarily \\
\hline & 7) When I'm happy and feel that things are going well \\
\hline Negative emotions and potentially critical situations & 13) When I want to celebrate a birthday, an anniversary or a holiday \\
\hline & 3) When I feel everything is going wrong \\
\hline & 5) When there are disputes or conflicts in family \\
\hline Habit and Abstinence & 17) When I feel depressed \\
\hline & 21) When I face a problem or something that worries me \\
\hline & 6) When it springs to mind and I think of heroin \\
\hline
\end{tabular}

each other, and predictive of a visual analogue measure of craving.

\section{Sample}

The scale was administered to 80 subjects enrolled in the Servizio Tossicodipendenze (SerT) ${ }^{1}$ in the city of Pisa. The choice of the sample followed a convenience criterion enrolling patients with psychological therapy and/or pharmacological replacement treatments. The heroin version was administered to 42 subjects and the cocaine version to 38 . This choice took the primary substance addiction into account.

\section{RESULTS}

Table 3 shows mean scores for subscales and total score calculated on the total sample, and for the primary substance of use.

Means comparison on abuse substance (Heroin and Cocaine) were carried out, in order to identify any differences in the scale and subscale totals (see Table 3). A significant difference with regard to Positive emotions and social situations - Coping self-efficacy scale $(\mathrm{t}=2038$; $\mathrm{df}=$ $61, \mathrm{p}<0.05)$ and a trend towards significance for the subscale
Positive emotions and social situations - Desire $(\mathrm{t}=1768$; $\mathrm{df}$ $=61, \mathrm{p}=0.81$ ) emerges. Heroin users show significantly higher scores than cocaine users in coping self-efficacy, in social situation subscales characterized by positive emotions.

Other comparisons within subscales, on the total sample and within groups of users of heroin and cocaine were made. It is interesting to observe that differences in the scores of all subscales are not significant on the total sample while differences in subscales are significant (see Table $\mathbf{4}$ and Table 5).

\section{Internal Consistency Analysis}

Internal consistency for Desire total scale is excellent, with a Cronbach coefficient of 0.94 , with $93 \%$ of the item presenting a greater than 0.40 item-total correlation.

Reliability with Split-half method is also explored: the correlation between the two halves is (Spearman-Brown) $=0.93$.

For Coping self-efficacy scale, Cronbach coefficient is good $(=0.97)$, with $96 \%$ of the items presenting an item-total correlation greater than 0.50. Reliability, calculated by Splithalf method (Spearman-Brown) is 0.96 .

The correlation between Desire scale and Coping selfefficacy scale is $-0.81(\mathrm{p}<0.0001)$.

\section{Table 3. Means and Standard Deviation}

\begin{tabular}{|c|c|c|c|c|c|c|}
\hline & \multicolumn{2}{|c|}{ H version } & \multicolumn{2}{|c|}{$\mathrm{C}$ version } & \multicolumn{2}{|c|}{ Total sample } \\
\hline & Desire level & $\begin{array}{l}\text { Coping self- } \\
\text { efficacy }\end{array}$ & Desire level & $\begin{array}{l}\text { Coping self- } \\
\text { efficacy }\end{array}$ & Desire level & $\begin{array}{l}\text { Coping self- } \\
\text { efficacy }\end{array}$ \\
\hline Positive emotions and social situations & $34.4(17.8)$ & $60.0(17.6)$ & $41.8(15.4)$ & $51.3(16.4)$ & $37.7(16.8)$ & $55.5(18.4)$ \\
\hline $\begin{array}{l}\text { Negative emotions and potentially critical } \\
\text { situations }\end{array}$ & $40.9(23.7)$ & $53.9(21.8)$ & $35.6(19.9)$ & $60.1(17.9)$ & $38.4(22.1)$ & $56.0(21.4)$ \\
\hline Habit and abstinence & $37.8(21.7)$ & $56.0(20.9)$ & $40.5(16.4)$ & $57.2(16.4)$ & $38.3(19.0)$ & $56.0(19.8)$ \\
\hline Total score & $113.1(60.3)$ & $169.9(56.4)$ & $117.8(45.5)$ & $168.6(46.0)$ & $114.5(53.2)$ & $167.5(56.3)$ \\
\hline
\end{tabular}

Total sample: $\mathrm{N}=80$; Heroin as primary substance: $\mathrm{N}=42$; Cocaine as primary substance: $\mathrm{N}=38$

Desire scale: Item mean $=4.2$; Minimum $=2.4$; Maximum $=5.8$

Coping self-efficacy scale: Item mean $=6.2$; Minimum $=4.5$; Maximum $=8.0$

$\mathrm{H}$ version $=$ Heroin version $; \mathrm{C}$ version $=$ Cocaine version

${ }^{1}$ SerT is the main public service treatment centre of addiction in the area of Pisa. 
Table 4. Comparisons between Subscales within Groups (Main Substance Abuse: Heroin - N =42)

Heroin consumers

Desire level is significantly higher in Negative emotions and potentially critical situations scale, compared to Positive emotions and social situations scale ( $\mathrm{t}$ $=2870 ; \mathrm{df}=41, \mathrm{p}<0.01)$. Coping self-efficacy is significantly higher in Positive emotions and social situations scale compared to Negative emotions and potentially critical situations scale $(\mathrm{t}=3553 ; \mathrm{df}=41, \mathrm{p}<0.001)$ and respect to Habit and abstinence scale $(\mathrm{t}=2864 ; \mathrm{df}=41, \mathrm{p}<0.01)$

Table 5. Comparisons between Subscales within Groups (Main Substance Abuse: Cocaine - N =38)

Cocaine consumers

Desire level is significantly higher in Positive emotions and social situations scale compared to Negative emotions and potentially critical situations scale ( $\mathrm{t}$ $=2246 ; \mathrm{df}=37, \mathrm{p}<0.05)$. Coping self-efficacy is significantly higher in Negative emotions and potentially critical situations scale compared to Positive emotions and social situations scale $(\mathrm{t}=3427 ; \mathrm{df}=37, \mathrm{p}<0.01)$ and compared with Habit and abstinence scale $(\mathrm{t}=3322 ; \mathrm{df}=37, \mathrm{p}<0.01)$

\section{Convergent Validity}

Visual Analogue Scale is positively correlated with Desire scale $(\mathrm{r}=0.61, \mathrm{p}<0.01)$ and all three subscales: respectively Positive emotions and social situations $(\mathrm{r}=0.49$, $\mathrm{p}<0.01$ ), and Negative emotions and potentially critical situations $(\mathrm{r}=0.62, \mathrm{p}<0.01)$, Habit and abstinence $(\mathrm{r}=0.57$, $\mathrm{p}<0.01)$ and negatively correlated with Coping self-efficacy scale $(\mathrm{r}=-0.82, \mathrm{p}<0.01)$ and all three subscales: respectively Positive emotions and social situations $(\mathrm{r}=-0.74, \mathrm{p}<0.01)$, Negative emotions and potentially critical situations $(\mathrm{r}=-$ $0.82, \mathrm{p}<0.01)$, Habit and abstinence $(\mathrm{r}=-0.78, \mathrm{p}<0.01)$.

It is interesting to observe how the Visual Analogue Scale does not discriminate between substance abuse while Coping self-efficacy scale for positive emotions and social situations does.

\section{Structural Model}

We used the technique of structural equations models (SEM) to verify the adequacy of the model. The model has six endogenous observed variables concerning subscales, each with its error component, two latent variables relating to Desire and Self-efficacy constructs, these linked in a further observed endogenous variable defined by scoring of Visual Analogue Scale (SAV).

The software Amos version $16.0[43,44]$ was used to develop this analysis with the method of maximum likelihood estimation procedure. Indexes for model evaluation, following Browne and Mels directions [45], are the following:

CMIN: this outlines the difference between the covariance matrix of the above hypothetical model and the covariance matrix observed by empirical data. A significant value of CMIN (p-value) indicates that the hypothetical model deviates from the data.

$C M I N / d f$ : the values recommended for a decent adaptation between hypothetical model and data are between 1.0 and 2.0 with values close to 1.0 for the most correct ones [46].

FMIN: this measure introduces the use of the discrepancy population function rather than sample function, to assess the adequacy of the model [47]. HI and LO present confidence intervals at $90 \%$ for the value of the population.
Root Mean Square Error of Approximation (RMSEA): acceptable values are between 0.05 and 0.08 . Values of 0.05 or lower indicate an excellent adequacy of the model [44].

Comparative Fit Index (CFI): this varies between 0 and 1 ; values close to 1 and above 0.90 indicate an excellent adaptation to the data [48].

The level of significance of the regression parameters for the relationship between variables is indicated by the Critical Ratio (CR) greater than $1.96(\mathrm{p}<0.05)$.

The proposed structural model is presented in Fig. (1), while indexes used are reported in Table 6. We observed that all indicators show a good adaptation of the model to the data.

Table 6. Indices Used for the Evaluation of the Model

\begin{tabular}{|l|c|c|c|c|c|}
\hline CMIN & $\boldsymbol{p}$-value & CMIN/df & FMIN (HI-LO) & RMSEA & CFI \\
\hline \hline 10.561 & 0.393 & 1.056 & $0.129(0.000-0.154)$ & 0.026 & 0.999 \\
\hline $\mathrm{df}=10$
\end{tabular}

From Fig. (1) it is interesting to observe the squared multiple correlation associated with the subscales. They represent the percentage of the explained variance and they are all significant and greater than 0.70. Moreover, the observed variable VAS is explained by the linear combination of two latent variables (Desire and Self-efficacy) that are capable, in turn, of predicting the observed variables represented by subscale scores. If we consider VAS as a generally used measure of craving, it is interesting to note that $70 \%$ of the variance is explained by latent variables Self-efficacy and Desire and indicates a good predictive ability of these factors. We can note that each observed variable has a variable error associated with it. It is assumed that, in empirical data, the prediction is never perfect but is subject to measurement errors or to influence of other variables not taken into account in the model.

For example, the variable error associated with the VAS is much more than a random fluctuation in scores due to measurement errors. It is everything craving may be associated with, but it is not measured in this study.

From Fig. (1) we can see estimated standardized regression coefficients. As far as the subscales are concerned, they 


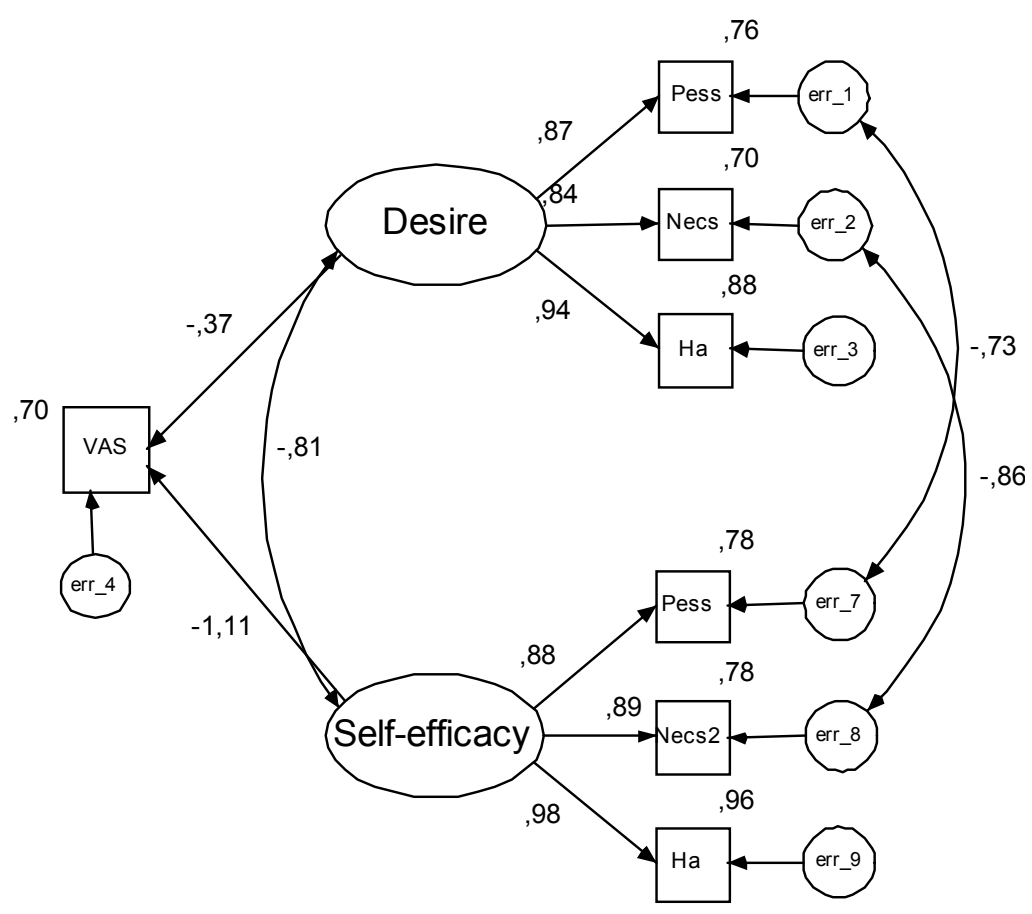

Fig. (1). Graphical representation of structural model.

Notes: VAS = Visual Analogue Scale; Pess = Positive emotions and social situations; Necs = Negative emotions and potentially critical situations; $\mathrm{Ha}=$ Habit and abstinence.

are all significant $(\mathrm{p}<0.01)$ and exceed 0.80 highlighting a good predictive power, consistently within the values of latent variables Desire and Self-efficacy on their subscales. Regarding the relationship between the Visual Analogue Scale and latent model factors, the predictive power factor Self-efficacy $(\beta=-1.11, \mathrm{p}<0.01)$ is greater than factor Desire $(\beta=-0.37, \mathrm{p}<0.05)$.

Finally we find the correlation between the two latent factors Desire and Self-efficacy $(r=-0.81, p<0.01)$ and the correlation between the errors of measurement of subscales significant. (Respectively, $\mathrm{r}=-0.73, \mathrm{p}<0.05$ and $\mathrm{r}=-0.86$, $\mathrm{p}<0.05)$.

\section{DISCUSSION}

\section{Considerations Regarding the Clinical Use of the Scale}

Clinicians underline the utility of the scale with their patients in guiding the interview on psychological constructs relevant to craving and the ability to deal with it. If beliefs about Coping self-efficacy on the use of substances are associated with specific situations, a multi-dimensional tool, including potential risk situations, is an optimal guide for clinical work addressing the strengthening of low selfefficacy areas.

The scores can be easily calculated and help guide the patient to focus on:

- What the most difficult situations associated with desire for the substance and the perceived coping ability are;
- The relationship which is usually inversely proportional between desire and coping selfefficacy (if desire decreases, self-efficacy increases and conversely) and in which cases it does not appear;

- Which is the most critical among the subscales;

- What the coping strategies used to deal with the moments of greatest desire are (clinicians may subsequently orient treatments on development and testing of functional strategies).

If there has been a previous administration with the same subject, it can be very useful to compare the two scales longitudinally. As a consequence, clinicians have noted that it is possible to further explore constructs of desire and coping self-efficacy in relation to the temporal dimension and according to the therapeutic treatment. For instance, V., nearly two months after starting a daily program for patient observation and diagnosis, in combination with a weekly psychological treatment, was compared in the two scales. We observed the level of desire for heroin had not changed between the first and second administration of the scale while the score on the perceived coping self-efficacy nearly tripled. These considerations made it possible, in the psychological treatment, to study the implications of these processes.

Multidimensionality is an advantage, in that we are able to grasp the nuances that scales with a single item inevitably lose. The scale directs the interview leading both to an investigation with the patient of situations that can really occur and to the discovery of individual strategies that can be 
adopted to cope with difficult situations. When used with the same individual over a period of time, it can record the performance of desire and the coping self-efficacy in relation to his therapeutic treatment. Emerging methodological considerations also lead us to prefer multidimensional scales. Scales with a single item make measurement very unreliable as the presence of random errors inevitably leads to sub / overestimation of the scores. In the case of multiple items, random errors in the items tend to be offset by making a more accurate and safe measurement. So by increasing the number of items the reliability of the measurement is also increased, particularly in cases where the error component in the individual item is sensitive. The SAD is also able, unlike the Visual Analogue Scale, to discriminate between substances of abuse. This is an added benefit as it demonstrates a greater sensitivity from a methodological point of view.

Finally, the model analysed in this article shows an excellent adaptation to the data and confirms the construct validity of Desire and Coping self-efficacy in predicting craving.

\section{Limitations of the Study}

Caution is required when using the terms desire and coping self-efficacy because the evaluation instrument was developed in the Italian language. Their translation into English may be affected by cultural and interpretational differences.

The criterion of convenience in the choice sample may have led to select subjects with characteristics that differentiate them from the population of the SerT (for example in terms of motivation).

Moreover, some patients may not have experienced some of the situations just presented. This may have affected the reliability of the answers. The self-efficacy scores resulting from circumstances of uncertainty could be unstable.

\section{REFERENCES}

[1] Sayette MA, Shiffman S, Tiffany SF, Niaura RS, Martin CS, Shadel WG. The measurement of drug craving. Addiction 2000; 95: 189-210

[2] Tiffany ST. A critique of contemporary urge and craving research: Methodological, psychometric, and theoretical issues. Adv Behav Res Ther 1992; 14: 123-39.

[3] Moos RH. Theory-based active ingredients of effective treatments for substance use disorder. Drug Alcohol Depend 2007; 88: 10921.

[4] Moos RH. Theory-based processes that promote the remission of substance use disorders. Clin Psychol Rev 2007; 27: 537-51.

[5] Berger SP, Hall SM, Mickalian JD, Reid MS, Crawford CA, Delucchi KL, Carr K, Hall S. Haloperidol antagonism of cue-elicitd cocaine craving. Lancet 1996; 347: 504-8.

[6] Da Silveira DX, Fernandes M, Silveira ED, Jorge MR. Cocaine craving questionnaire: Assessing craving among cocaine users in Brazil. Psychol Res 2006; 142: 257-9.

[7] Da Silveira DX, Silveira ED, Niel M, Jorge MR. Predicting craving among cocaine users. Addict Behav 2006; 9: 2292-7.

[8] Rosenberg H, Mazzola J. Relationships among self-report assessments of craving in binge-drinking university students. Addict Behav 2007; 32: 2811-8.

[9] Waters AJ, Carter BL, Robinson JD, Wetter DW, Lam CY, Cinciripini PM. Implicit attitudes to smoking are associated with craving and dependence. Drug Alcohol Depend 2007; 91: 178-86.

[10] Ogai Y, Haraguchi A, Kondo A, Ishibashi Y, Umeno M, Kikumoto H, Hori T, Komiyama T, Kato R, Aso K, Asukai N, Senoo E, Ikeda
K. Development and validation of the Stimulant Relapse Risk Scale for drug abusers in Japan. Drug Alcohol Depend 2007; 88: 174-81.

[11] Tiffany ST, Singleton E, Haertzen CA, Henningfield JE. The development of a cocaine craving questionnaire. Drug Alcohol Depend 1993; 34: 19-28.

[12] Voris J, Elder I, Sebsastian P. A simple test of cocaine craving and related responses. J Clin Psychol 1991; 47: 320-3.

[13] Hayes MHS, Patterson DG. Experimental development of the graphic rating scale. Psychol Bull 1981; 18: 98-9.

[14] Maxwell C. Sensitivity and accuracy of the Visual Analogue Scale: A psycho-phisical classroom experiment. Br J Clin Pharmacol 1978; 6: 15-24.

[15] Nicholson AN. Visual Analogue Scales and drug effects. Br J Clin Pharmacol 1978; 6: 3-4.

[16] Franken HA, Hendriks VM, Van Den Brink W. Initial validation of two opiate craving questionnaires: The Obsessive Compulsive Drug Use Scale and the Desires for Drug Questionnaire. Addict Behav 2002; 27: 675-85.

[17] Heinz AJ, Epstein DH, Schroeder JR, Singleton EG, Heishman SJ, Preston KL. Heroin and cocaine craving and use during treatment: Measurement validation and potential relationships. J Subst Abuse Treat 2006; 31: 355-64.

[18] Sussner BD, Smelson DA, Rodrigues S, Kline A, Losonczy M, Ziedonis D. The validity and reliability of a brief measure of cocaine craving. Drug Alcohol Depend 2006; 83: 233-7.

[19] Schuster CR, Greenwald MK, Johanson CE, Heishman SJ. Measurement of drug craving during naloxone-precipitated withdrawal in methadone-maintained volunteers. Exp Clin Psychopharmacol 1995; 3: 424-31.

[20] Bandura A. Self-efficacy: The excercise of control. Freeman and Company: New York, 1997.

[21] Bandura A. Self-efficacy: Toward a unifyng theory of behavioral change. Psy Review 1977; 84: 191-215.

[22] Caprara GV. La valutazione dell'autoefficacia. Costrutti e strumenti. Erickson: Trento, 2001.

[23] Caso D. L'autoefficacia riferita alla salute: un contributo all'integrazione e alla validazione delle scale di misurazione dell'autoefficacia percepita specifiche per la salute. Psicologia della Salute 2003; 1 .

[24] Levin C, Ilgen M, Moos R. Avoidance Coping Strategies Moderate the Relationship Between Self-Efficacy and 5-Year Alcohol Treatment Outcomes. Psychol Addict Behav 2007; 21: 108-13.

[25] Sklar SM, Annis HM, Turner NE. Development and validation of the Drug-Taking Confidence Questionnaire: A measure of coping self-efficacy. Addict Behav 1997; 22: 655-70.

[26] Annis HM, Graham, JM. Profile types on the Inventory of Drinking Situations: Implications for relapse prevention counseling. Psychol Addict Behav 1995; 9: 176-82.

[27] Breslin FC, Sobell LC, Sobell MB, Agrawal SA. Comparison of a brief and long version of the Situational Confidence Questionnaire. Behav Res Ther 2000; 38: 1211-20.

[28] Martin GW, Wilkinson DA, Poulos CX. The drug avoidance selfefficacy scale. J Subst Abuse 1995; 7: 151-63.

[29] Turner NE, Annis HM, Sklar SM. Measurement of antecedents to drug and alcohol use: Psychometric properties of the Inventory of Drug-Taking Situations (IDTS). Behav Res Ther 1997; 35: 465-83.

[30] Gaily SE, Sheikh E, Bashir TZ. High-risk relapse situations and self-efficacy: Comparison between alcoholics and heroin addicts. Addict Behav 2004; 29: 753-8.

[31] Haaga D, Hall SM, Haas A. Participant factors in treating substance use disorders. In: Castonguay LG, Beutler LE, Eds. Principles of therapeutic change that work. Oxford, New York, 2006; pp. 275-92.

[32] Piotrowski NA, Sees KL, Reilly PM. Self-efficacy profiles and treatment response in opioid abusers. Pharmacol Biochem Behav 1994; 48: 837-49.

[33] Reilly PM, Sees KL, Shopshire MS, Hall SM, Delucchi KL, Tusel DJ, Banys P, Clark HW, Piotrowski NA. Self-efficacy and illicit opioid use in a 180-day Methadone detoxification treatment. J Consult Clin Psychol 1995; 63: 158-62.

[34] Sitharthon T. The role of efficacy expectations in the treatment of drug and alcohol problems. National Drug and Alcohol Research Center 1989; 7.

[35] Sitharthon T, Kavanagh DJ. Role of self-efficacy in predicting outcomes from a program for controlled drinking. Drug Alcohol Depend 1990; 27: 87-94. 
[36] Walitzer KS, Dearing RI. Gender differences in alcohol and substance use relapse. Clin Psychol Rev 2006; 26: 128-48.

[37] Rychtarik RG, Prue SR, Rapp AC. Self-efficacy, aftercare, and relapse in a treatment program for alcoholics. J Stud Alcohol 1992; 53: 435-40.

[38] Walton MA, Blow FC, Bingham CR, Chermack ST. Individual and social/environmental predictors of alcohol and drug use 2 years following substance abuse treatment. Addict Behav 2002; 28: 62742.

[39] Greenfield SF, Hufford MR, Vagge LM, Nuenz LR, Costello ME, Weiss RD. The relationship of self-efficacy expectancies to relapse among alcohol dependent men and women: A prospective study. J Stud Alcohol 2000; 61: 345-51.

[40] Allsop S, Saunders B, Phillips M. The process of relapse in severely dependent male problem drinkers. Addiction 2000; 95: 95106.

[41] Ilgen M, Mckellar J, Tiet Q. Abstinence self-efficacy and abstinence one year after substance use disorder treatment. J Consult Clin Psychol 2005; 73: 1175-80.
[42] McKay JR, Foltz G, Stephens RC, Leahy PJ, Crowley EM, Kissin W. Predictors of alcohol and crack cocaine use outcomes over a 3year follow-up in treatment seekers. J Subst Abuse Treat 2005; 28: 73-82.

[43] Arbuckle JR. Amos 16.0 user's guide. Amos Development Corporation: Spring House, PA, USA, 2007.

[44] Browne MW, Cudeck R. Alternative ways of assessing model fit. In: Bollen KA, Long JS. Eds. Testing structural equation models. Sage Publications: Newbury Park, CA, 1993; pp. 136-62.

[45] Browne MW, Mels G. RAMONA user's guide. The Ohio State University: Columbus, OH, 1992.

[46] Wheaton B, Muthén B, Alwin DF, Summers GF. Assessing reliability and stability in panel models. In: Heise DA, Eds. Sociological methodology, Jossey-Bass: San Francisco 1997; pp. 84-136.

[47] Steiger JH, Lind JC. Statistically-based tests for the number of common factors (A): Annual Spring Meeting of the Psychometric Society, Iowa City, 1980.

[48] Bentler PM. Comparative fit indexes in structural models. Psychol Bull 1990; 107: 238-46.

Received: December 12, 2010

Revised: January 25, 2011

Accepted: February 05, 2011

(C) Minervini et al.; Licensee Bentham Open .

This is an open access article licensed under the terms of the Creative Commons Attribution Non-Commercial License (http://creativecommons.org/ licenses/by-nc/3.0/), which permits unrestricted, non-commercial use, distribution and reproduction in any medium, provided the work is properly cited. 